Article

\title{
Intelligence-Based Battery Management and Economic Analysis of an Optimized Dual-Vanadium Redox Battery (VRB) for a Wind-PV Hybrid System
}

\author{
Hina Fathima $\mathrm{A}^{1, * \mathbb{C}}$, Kaliannan Palanisamy ${ }^{2}$, Sanjeevikumar Padmanaban ${ }^{3, *(1)}$ and \\ Umashankar Subramaniam ${ }^{2}$ \\ 1 Hindustan Computer Limited (HCL) Technologies Ltd., Chennai 600058, Tamil Nadu, India \\ 2 School of Electrical Engineering, VIT University, Vellore 632509, Tamil Nadu, India; \\ kpalanisamy79@gmail.com (K.P.); umashankar.s@vit.ac.in (U.S.) \\ 3 Department of Energy Technology, Aalborg University, 6700 Esbjerg, Denmark \\ * Correspondence: hina.fathima49@gmail.com (H.F.A); san@et.aau.dk (S.P.); Tel.: +91-989-404-0497 (H.F.A)
}

Received: 13 September 2018; Accepted: 1 October 2018; Published: 17 October 2018

\begin{abstract}
This paper proposes an intelligent battery management system (BMS) implementing two large Vanadium Redox Battery (VRB) flow batteries in a master-slave mode to provide grid-level energy storage for a wind-solar hybrid power system. The proposed BMS is formulated to effectively meet a predetermined power dispatch formulated based on forecasted wind and solar data while incorporating features like peak shaving and ramp rate limiting. It is compared to a single battery module operated system to showcase the advantages of the proposed intelligent dual battery module in terms of appreciable reduction in battery size and costs while exhibiting improved lifecycle performance. The battery size is optimized based on heuristic optimization algorithms and modelled in Matlab/Simulink environment. An intelligent fuzzy-based BMS is used to control the dual VRB model to ensure optimized power sharing between batteries. The simulations were carried out and an in-depth economic analysis conducted to analyze the costs and other financial metrics of the hybrid project. Results proved the advantages of the dual battery with the proposed BMS and fortify that the introduction of time-based tariffs and other incentives will further make investments in VRB highly attractive for renewable applications.
\end{abstract}

Keywords: VRB; battery management; dispatch; energy management; wind; dual-battery

\section{Introduction}

India is currently well placed on its path to address climate change with the Indian government announcing ambitious renewable projects. India aims to achieve $100 \mathrm{GW}$ solar power and $60 \mathrm{GW}$ of wind power by 2022. Wind energy generation capacity in India amounts to $67.9 \%$ of total renewable energy capacity by 2017. However, wind generation faces many issues and extensive investments are made for vast repowering activities for wind farms in India [1]. Hybrid Renewable Energy Systems (HRES) integrating renewable power generating units with storage options will aim to increase the utilization of available land and help in achieving the solar targets. Multi-purpose repowering by integrating solar Photovoltaics (PV) with the existing wind turbines is being proposed with smart metering. Energy storage systems are increasingly being viewed as an effective solution in hybrid systems with higher renewable penetration to ensure system flexibility and reliability, thus replacing fossil driven dispatch able plants [2-4]. Other solutions like Demand Side Management also allow for greater renewable penetration in modern micro grids but are often limited by available capacity and customer comfort in intelligent management of microgrids [5]. 
Battery Energy Storage Systems (BESS) are found to be the most widely implemented storage solutions for wind-PV systems [6-8]. Many studies are now proposed on optimization [9] and economic studies [10] integrating batteries. Flow batteries prove to be good investment solutions for grid-level storage requirements with their large capacity and modularity in a detailed study conducted for Wind-PV-Battery systems [11]. Advances in electrolyte and cell technology have brought down energy costs considerably. Unlimited use of recyclable electrolyte [12] provides umpteen number of operating cycles with little self-discharge and a long shelf life which makes it more attractive for grid level renewable applications. Vanadium Redox Battery (VRB) is a type of flow battery, which is predicted to capture a significant share of the future energy storage markets [13]. VRBs have been implemented in many renewable systems in the world and are listed in the Department of Energy (DOE) database [14].

Energy Management Systems (EMS) are essential for batteries to ensure optimal operation and effective service lifetime. Control and management strategies influence the performance of storage systems as explored in the case of a battery integrated hybrid microgrid in [8,15-18]. Refs $[19,20]$ presented a scheme to utilize two batteries in dual-topology to dispatch wind power where the two batteries were used interchangeably for charging and discharging to deliver wind power with better forecasting and increased reliability. Ensuring full charge/discharge cycle of batteries has proved to improve the operating lifetime of batteries [21]. A control strategy for multiple BESS units with individual battery modules dispatched in a rank-based strategy ensured equal battery lifetimes and better performance [22]. Intelligent controllers based on fuzzy logic can also ensure optimized and efficient control of hybrid systems integrating renewables and storage systems [23]. The above ideas prove that control and management of storage in an HRES can be effectively planned to enhance system performance and storage life. However, modifying these strategies to be implemented with large scale flow battery systems is the core idea of the study.

In India, with the government aiming to encourage renewable penetration, it is high time to explore the concept of integrating and managing energy storage for renewables based on Indian climatic and market conditions. Modelling and operation of flow batteries is still being explored in current literature. The proposed study explores sizing and operation of flow batteries for Indian market conditions by modelling and integrating the VRB as single and dual battery modules in separate cases. The main objective of the paper is to study and analyze the performance of the VRB under two different topologies. The study methodology includes: (i) forecasting and scheduling of HRES output including peak shaving and ramp rate limiting for grid integration; (ii) battery sizing and energy management strategies and (iii) techno-economic analysis of the battery performance for both cases. Thus, this article aims to provide a complete solution pathway for VRB implementation with the HRES and also evaluates and justifies its economic investment case.

The paper is structured as follows. Section 2 includes modelling of system components, solar and wind forecasting and the scheduling of HRES power. In Section 3, an optimal size of the battery is evaluated using bat optimization algorithm and in Section 4, the battery is operated as per the two different cases. In the first case, the VRB is used as a single battery and in the second case; the battery is implemented as a dual-VRB system with a fuzzy logic controller, which manages power sharing and switching of the dual battery. Section 5 discusses the simulated results and battery performance under the two cases based on battery's State of Charge $(S O C)$ and other economic parameters. All simulations are carried out in Matlab/Simulink.

\section{System Modeling and Power Dispatch Scheduling}

A test HRES is considered for the study, which consists of a $200 \mathrm{~kW}$ MICON M450-200 wind turbine and a $75 \mathrm{~kW}$, PV panel supplying power to the local grid [11]. Intermittencies in the wind and solar power make it highly unsuitable for power scheduling and grid integration, leading to heavy losses in the form of spilling and load shedding. Energy storage needs to be sized and operated to improve the HRES power dispatch, which is scheduled, based on the wind and solar forecast data. A VRB is selected due to its modularity in operation, high-energy capacity and high cycle life. 
Figure $1 \mathrm{a}$ is the schematic diagram of the proposed hybrid system and Figure $1 \mathrm{~b}$ shows the single and dual battery models. The wind turbine generates AC power and the solar panel and the VRB are connected to the AC grid through converters. Charge controllers used for the VRB in the simulation are bi-directional buck-boost converters. The energy management system performs the switching and controlling operations of the charge controllers to enable reliable operation of the HRES.

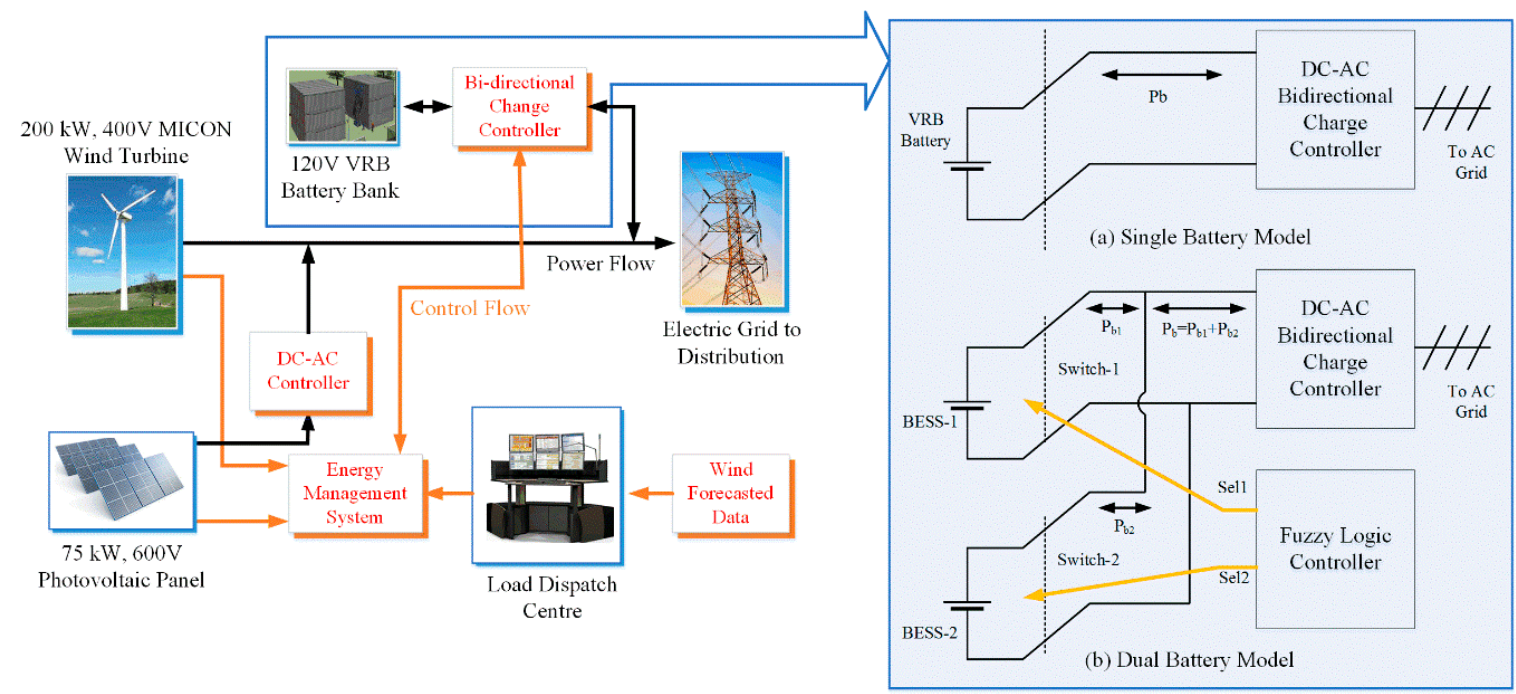

Figure 1. (a) Wind-Photovoltaic-Vanadium Redox Battery (VRB) Hybrid Renewable Energy System (HRES) (b) Subsection showing architecture for Single and Dual VRB battery modules as proposed.

\subsection{Wind Turbine Model}

The turbine starts generating power $P_{w}(t)$ once wind speed $v(t)$ exceeds cut-in speed $v_{c i}$ up until wind speed reaches the rated speed $v_{r}$ as in the relation (1). As per Betz law, a power coefficient $C_{p}$ governs the output power curve based on tip-speed ratio $\lambda$ and pitch angle $\beta$. At rated speeds $v_{r}$, the turbine generates rated power $P_{\text {rated-wt }}$ and continues until the cut-off speeds $v_{c o}$ are reached, beyond which the turbine is stalled for protection $[11,24]$.

$$
P_{w}(t)=\left\{\begin{array}{c}
0, v(t) \leq v_{c i} \text { or } v(t) \geq v_{c o} \\
0.5 \rho A C_{p}(\lambda, \beta) v(t)^{3}, v_{c i} \leq v(t) \leq v_{r} \\
P_{\text {rated }-w t,}, v_{r} \leq v_{c o}
\end{array}\right.
$$

\subsection{Solar Model}

Let $P_{p v}$ be the power produced from a solar panel of rated power $Y p v$. Let $G_{S T C}$ and $T_{S T C}$ be the irradiance and temperature incident on the panel under standard test conditions, assumed to be $1000 \mathrm{~W} / \mathrm{m}^{2}$ at $25^{\circ} \mathrm{C}$ respectively. Then the expression in (2) is used to evaluate the power generated from a solar panel at time $t$ when $G_{c}(t)$ is the irradiance in W/sq.m incident on the panel with an operating temperature $T_{c}(t){ }^{\circ} \mathrm{C} . \alpha$ is the temperature co-efficient of panel and $f_{p v}$, the derating factor, normally accounts for conditions like soiling, shading, snow cover etc. Based on the environmental conditions of the site, $\alpha$ and $f_{p v}$ are assumed to be $0.04 \%$ and $94 \%$ respectively [11].

$$
P_{p v}(t)=Y_{p v} f_{p v} \frac{G_{\mathcal{C}}(t)}{G_{S T C}}\left[1+\alpha\left(T_{\mathcal{C}}(t)-T_{S T C}\right)\right]
$$

The cumulative power generated by the HRES $P_{g e n}(t)$ is found after considering efficiencies of wind and PV systems as shown in (3).

$$
P_{g e n}(t)=\left(P_{w}(t) \times \eta_{w t}\right)+\left(P_{p v}(t) \times \eta_{p v}\right)
$$




\subsection{Battery Model}

Since the 1980s, flow batteries storing electrolytes in separate tanks and circulating them into the battery have expanded the energy capacities of a battery and made the management of electrolytes easier. VRBs are capable of holding charge for long idle periods with almost zero self-discharge. Vanadium, a shiny soft metal used to improve the ductility of steel and soft iron became noted for its ability to gain and lose electrons and led to the exploration of a vanadium-based battery. The cost of vanadium was a major concern factor for the development of vanadium batteries. However, recycled vanadium from oil sludge and fly ash are being proposed with good results $[25,26]$. Scalability and operating ease have made VRB capable of operating with high capacities and short response times. Hence, VRBs are being considered for varied grid level storage applications including black start, supply reserves, frequency regulation, renewable integration, load levelling, energy arbitrage etc. [14]. A VRB is modelled as shown in Figure 2 below [27].

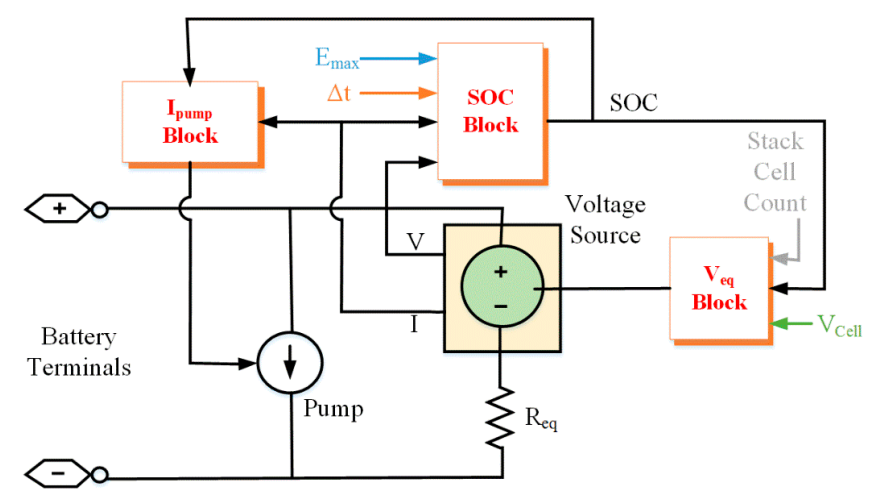

Figure 2. Block diagram of VRB battery.

The SOC of the battery is calculated as shown in (4)

$$
\operatorname{SOC}(t)=\operatorname{SOC}(t-1)+\frac{\left(P_{b}(t)\right) d t}{E_{\text {bess }} \times \eta}
$$

In the above equation, $P_{b}(t)$ denotes the power to be charged/discharged to/from the battery in $\mathrm{kW}$ and $E_{\text {bess }}$ is the VRB capacity in $\mathrm{kWh}$. $\eta$ is the efficiency of the VRB. The battery is modelled as a controlled voltage source by evaluating its cell stack voltage $\left(V_{\text {stack }}\right)$ and $\mathrm{n}$ as the number of cell stacks in the battery architecture. Equivalent cell voltage $V_{e q}$ is calculated as the product of the number of stack cells and the individual cell voltage $\left(V_{\text {cell }}\right)$ which is set to be $1.5 \mathrm{~V}$ found from experimental analysis of VRB systems in [13,14]

$$
V_{\text {stack }}=V_{\text {eq }}+2 \frac{R T}{F} \ln \left(\frac{S O C}{1-S O C}\right) \text { where } V_{\text {eq }}=n \cdot V_{\text {cell }}
$$

Extrinsic losses are fixed losses occurring in the external circuitry and the pumps. Equivalent resistance is obtained using internal and parasitic resistance

$$
R_{e q}=R_{i n t} \| R_{p a r}
$$

The current to the electrolyte circulating pumps $\left(I_{\text {pump }}\right)$ is expressed in terms of stack current $\left(I_{\text {stack }}\right)$ and state of charge $(S O C)$ of battery as per the below Equation [13]

$$
I_{\text {pump }}=1.011\left(\frac{I_{\text {stack }}}{\text { SOC }}\right)
$$




\subsection{Forecasting and Scheduling of Power Dispatch}

Indian states generating wind power currently lack mature wind/solar forecasting systems [28], which makes managing power intermittencies difficult and may lead to voltage/frequency disruptions and grid failure. Wind forecasting methods can be broadly classified into two areas viz. statistical and intelligent techniques [29-31]. A simple statistical method is employed here to forecast wind data using previously measured data with an error component $e(t)$ [20]. The forecast error is assumed to follow a random normal distribution with mean $\mu$ and standard deviation of $\sigma$. Forecasted wind speed $v_{f}(t)$ is calculated using actual wind speed $v$ as in (8), where $v_{r}$ is the rated output wind speed of the wind turbine.

$$
v_{f}(t)=v(t-1)+e(t) * v_{r}
$$

Solar data can also be predicted with statistical and intelligent learning approaches based on historical data [32]. Here, solar irradiance is predicted on a day-ahead basis using multiple linear regressions on historical data, which aims at minimizing the mean square error and enables dynamic interactions between variables. The regression model is given by the below equation

$$
G_{f}=G_{c} \beta_{f}+\epsilon
$$

where $G_{f}$ is the response variable to be predicted based on the predictor variable and $G_{c}$ 一the historical irradiation data. $\beta_{f}$ is the unknown parameter matrix and $\varepsilon$ the error.

Energy generated from renewables needs to be dispatched intelligently to the grid to ensure total evacuation. Many dispatch strategies have been proposed in the literature involving energy storage systems. Q. Li et al., [21] introduced a min-max strategy of power dispatch which was later improvised in [33] for achieving a better battery life. The Indian load dispatch centers follow a 15-min time block for dispatching the generated power. The scheduling is done every 30-min covering two time blocks. This is to ensure that any intermittency in the renewable power generated in this time period will be nullified by the VRB, to enable a steady HRES output. This leads to a better evacuation planning scenario for the grid operators. The determined schedule allows the VRB to save excess power generated at off-peak times and then discharge the saved power back to the grid at peak times. Let $\operatorname{Dem}(t)$ be the power to be dispatched from the HRES to be delivered at time $t$. Table 1 enlists the evaluation formulas for Dem $(t)$ with peak shaving. $P G_{a v}(i)$ is the average power generated from renewables $\left(P_{\text {gen }}\right)$ for $i^{\text {th }}$ day based on forecasting. Next, dispatch power Dem is checked for ramp rate limit violations to exert a maximum power evacuation limit. A ramp rate limit of $15 \mathrm{~kW}$ every $10 \mathrm{~min}$ is imposed, and any excess energy is directed to be managed by the VRB [11].

Table 1. Dispatch curve evaluation.

\begin{tabular}{ccc}
\hline Hour of Day & Demand Period & Dispatch $(\operatorname{Dem}(t))$ \\
\hline 00:00 to 07:00 & Morning off-peak & $P_{g e n}(t) / 2$ \\
07:00 to 11:00 & Morning peak & $P G_{a v}(i)+\left(P_{g e n}(t) / 2\right)$ \\
11:00 to 19:00 & Mid-day off-peak & $\left(P_{g e n}(t)+P G_{a v}(i)\right) / 2$ \\
19:00 to 23:00 & Evening peak & $P G_{a v}(i)+\left(P_{g e n}(t) / 2\right)$ \\
23:00 to 0:00 & Evening off-peak & $P_{g e n}(t) / 2$ \\
\hline
\end{tabular}

\section{Optimized Sizing of the VRB Flow Battery}

\section{Sizing Methodology}

The VRB flow battery needs to balance the power difference $P_{\text {diff }}(t)$ occurring between the forecasted scheduled power $\operatorname{Dem}(t)$ and the actual power generated $P_{\text {gen }}(t)$ :

$$
P_{\text {diff }}(t)=P_{\text {gen }}(t)-P_{\text {dis }}(t)
$$


Optimization is used to find the smallest possible battery size $\left(C_{v r b}\right)$ satisfying all constraints at minimum investment costs (IEEE Std. 1184 has been followed for sizing). It is to be understood that the smaller the battery size, the more difficult it is for the battery to meet $P_{\text {diff; }}$, thereby resulting in insufficient storage capacity and associated losses. Hence, the objective function is coined as in (8) to minimize battery cost while satisfying all other constraints listed in (16)-(19) [11,34]. The addition of loss components in the objective function tends to balance the battery size for optimum capacity. The objective function includes cost coefficients for investments $(\chi)$ and maintenance costs $(\gamma)$ with time factors $(C R F)$ (See Nomenclature)

$$
\text { Minimize Cost }=\left(C_{v r b} * \chi(1+\gamma)\right) * C R F+L C
$$

where $C R F=\frac{i d r(1+i d r)^{n}}{(1+i d r)^{n}-1}$ is the capital recovery factor and

$$
i d r=\frac{1+i r}{1+i f r}-1
$$

In the above equations, idr, ifr, ir are the discount rate, inflation rate and interest rate on investment evaluated for $n$ years of VRB battery life, LC denotes the summation of Shedding_Loss and Wind_spilling_loss calculated as below:

$$
\begin{gathered}
\text { Shedding losses }=\sum_{i=1}^{r}\left(\operatorname{Dem}(t)-P_{g e n}(t)\right) \times \Delta t \times P R_{d} \text { when Dem }>P_{g e n} \\
\text { Spilling losses }=\sum_{i=1}^{r}\left(P_{g e n}(t)-\operatorname{Dem}(t)\right) \times \Delta t \times P R_{w s} \text { when } \operatorname{Dem}<P_{g e n}
\end{gathered}
$$

Let the revenue earned by delivering $P_{\text {del }}(t)$ be evaluated based on the wind tariff of the region as

$$
\text { Revenue Earned }=\sum_{i=1}^{r} P_{d e l}(t) \times \Delta t \times P R_{w s}
$$

Constraints bounding the search algorithm are:

$$
\begin{gathered}
P_{g e n}(t)=\operatorname{Dem}(t)+P_{b}(t) \\
P_{g e n}(t) \leq P_{b}(t) \leq P_{b, \text { max }} \\
S O C_{\min } \leq S O C(t) \leq S O C_{\max }
\end{gathered}
$$

where

$$
\begin{gathered}
\operatorname{SOC}(t)=\operatorname{SOC}(t-1)+\frac{\left(P_{b}(t)\right) \times \Delta t}{C_{v r b}} \\
E_{b, \text { min }} \leq E_{b}(t) \leq E_{b, \text { max }}
\end{gathered}
$$

where $E_{b}(t)=\max \left\{\left(E_{b}(t-1)+\left(\Delta t \times P_{b}(t)\right) / \eta_{\text {dis }}\right), E_{b, \min }\right\}$; for discharging and

$$
E_{b}(t)=\min \left\{\left(E_{b}(t-1)+\frac{\Delta t \times P_{b}(t)}{\eta_{c h g}}\right), E_{b, \max }\right\} ; \text { for charging. }
$$

The optimization problem is solved using bat optimization algorithm. Xin-She Yang formulated Bat optimization algorithm in 2010 [35]. It is a nature-inspired optimization algorithm, which was derived from swarm intelligence wherein a group of microbats uses echolocation technique to find their prey. Many studies [36,37] have established that Bat algorithm can yield comparatively good search results. Initial conditions of the algorithm are set by defining the frequency $\left(Q_{\min }\right.$ and $\left.Q_{\max }\right)$, amplitude $\left(A_{i}\right)$ and rate $\left(r_{i}\right)$ of sound pulses emitted by the participating microbat solutions. The best 
solution is selected by identifying the solution with minimum cost $\left(x^{*}\right)$. Velocities and positions of all bats are updated as in Equation (7) and search is continued until convergence.

$$
\begin{array}{r}
Q_{i}=Q_{\min }+\left(Q_{\min }-Q_{\max }\right) \\
v_{i}^{t}=v_{i}^{t-1}+\left(x_{i}^{t}-x^{*}\right) * Q_{i} \\
x_{i}^{t}=x_{i}^{t-1}+v_{i}^{t}
\end{array}
$$

\section{Energy Management of Dual Battery}

In this section, the battery thus sized is implemented with two different management strategies. VRB can be operated as modules connected in series and parallel to scale up the voltage and current respectively. In the first case, the VRB is operated as a single model and the second case the VRB is implemented in form of a dual battery model to where the two VRB modules are operated in complementary fashion as shown in Figure $1 \mathrm{~b}$. The simulations are run, and results are compared with the dual battery model.

\subsection{Single Battery Model}

The VRB is operated as a single model, thus absorbing energy when $P_{g e n}>D e m$ and discharging otherwise as shown in Figure 3a. The battery SOC and the power limits are monitored to avoid any under or overcharging of the battery. At times of $S O C$ violations, the battery is idle and power losses are calculated.
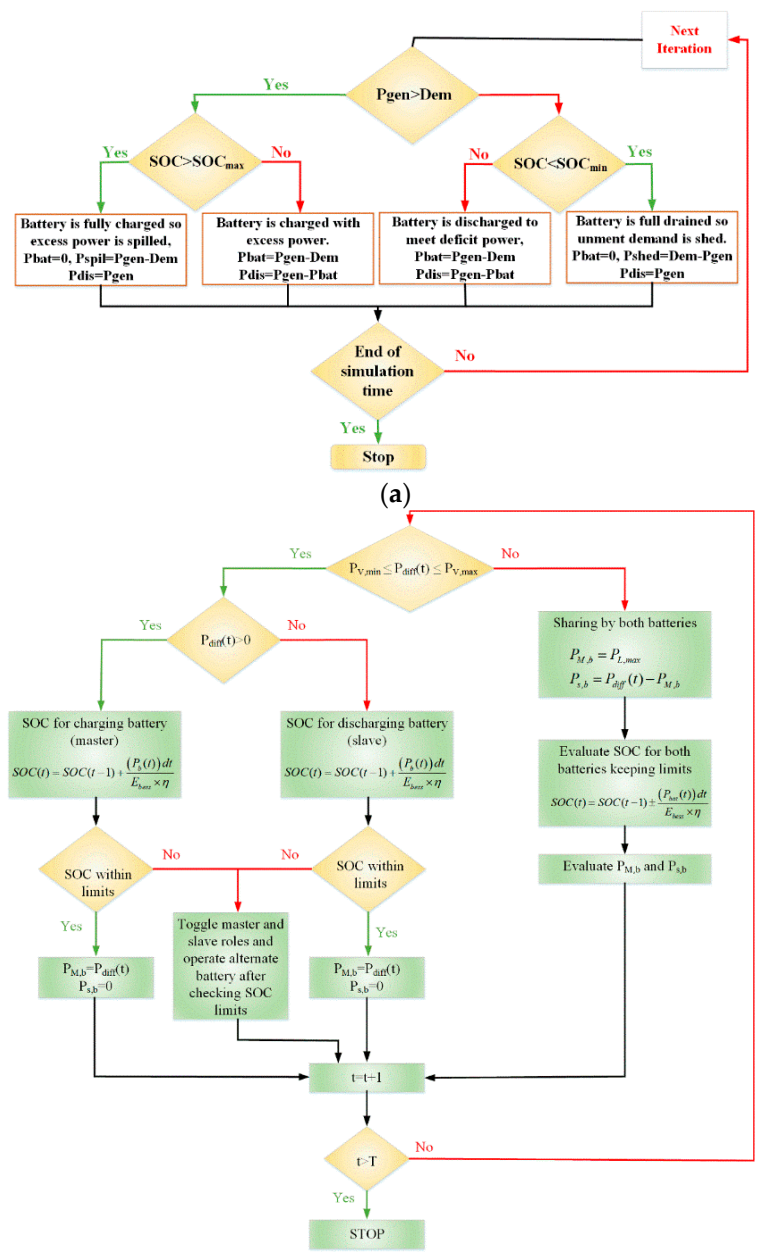

(b)

Figure 3. Flow chart for Energy Management Strategy for (a) Single battery case (b) Dual battery model case. 


\subsection{Dual Battery Model}

VRB is implemented as a Dual model with two VRB modules viz. BESS $S_{1}$ and $B E S S_{2}$ and the EMS for the dual module is depicted in Figure 3b. Each battery module is capable of operating independently with $B E S S_{1}$ in master-charging mode and $B E S S_{2}$ set to be in slave-discharging mode and vice versa. They toggle their roles on reaching their predetermined $S O C$ limits, i.e., when any one gets fully charged it is set to discharge and the other module charges respectively. The status of each battery can be indicated using select lines $\mathrm{Sel}_{1}$ and $\mathrm{Sel}_{2}$, which when high indicates the corresponding battery in master/charging mode. At times when the power difference to be met is greater than the maximum power limits $\left(P_{b, \max }\right)$ of single module i.e., $P_{\text {diff }}(t)>P_{b, \max }$, then the two batteries optimally share the power requirement based on their SOC. Hence, there arises a need to balance the sharing operation between the battery modules. This is implemented intelligently by a Fuzzy Logic Controller (FLC), which will decide the mutual sharing between modules based on their SOC and evaluate the power to be contributed by each battery module individually. Each fuzzy input is mapped to its member function (fuzzification) depending on its influence on the output. The output of each fuzzy set is inferred using fuzzy rules outlined in the controller. Defuzzification in the final step resolves the fuzzy outputs into a crisp number format $[23,38]$. In this study, the FLC designed is a mamadani type fuzzy system built from four inputs namely, power difference component $(d P), S O C$ of battery $B E S S_{1}\left(S O C_{1}\right), S O C$ of battery BESS $2\left(S O C_{2}\right)$ and $B E S S_{1}$ status signal $\left(S e l_{1}\right)$. The $d P$ is the power that is to be charged/discharged by the battery bank. The FLC takes information of battery capacity at each interval through its inputs $S O C_{1}$ and $S O C_{2}$ to ensure the batteries do not overcharge/over discharge. The outputs from the fuzzy system are two parameters $b_{1}$ and $b_{2}$ which in turn give the selection information of batteries $B E S S_{1}$ and $B E S S_{2}$ respectively.

Figure $4 \mathrm{a}-\mathrm{d}$ show the membership functions of inputs and outputs of FLC and trapezoidal functions are selected to represent them. SOCs are shown to be low $(L)$ or high $(H)$ or medium $(M)$. The $d P$ is shown to have four levels viz, Positive Big $(P B)$, Positive $(P)$, Negative Big $(N B)$ and Negative $(N)$. If $d P$ is positive and small $\left(<P_{b, \max }\right.$ limits) it is positive and if more than $P_{b, \max }$, it is Positive Big $(P B)$. Similarly, if $d P$ is negative and small $\left(<P_{b, \max }\right.$ limits) it is $\mathrm{N}$ and if more than $P_{b \text {, max }}$ it is Negative $\operatorname{Big}(N B)$. The output parameters $b_{1}$ and $b_{2}$ of the FLC denote the selection status of batteries. The $d P$ is checked for maximum battery power violations i.e., if abs $\left(P_{\text {diff }}(t)>P_{b, \max }\right)$, then it indicates a condition when both the batteries need to operate together to meet $P_{\text {diff }}(t)$. The optimal sharing in this condition is implemented based on the output parameters of the FLC and Lagrange's multipliers. A total of 18 fuzzy rules are outlined based on the energy management strategy in Figure $3 \mathrm{~b}$ and listed in Table 2 with all conditions and appropriate actions detailed.

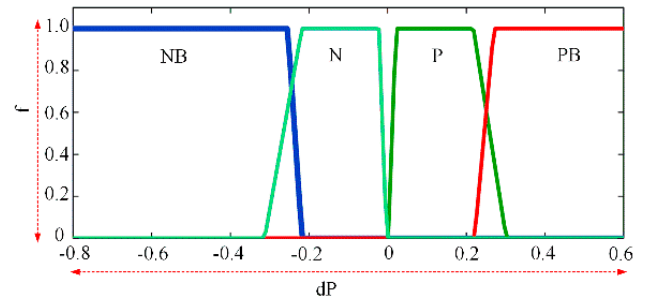

(a)

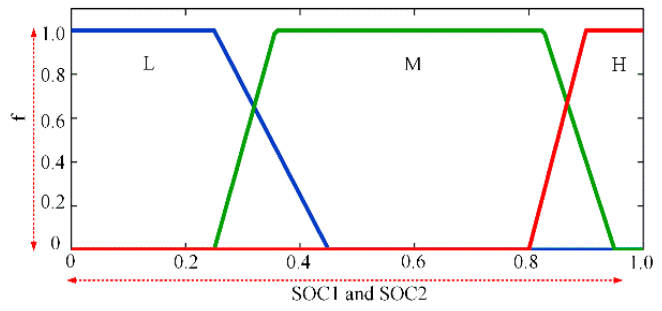

(c)

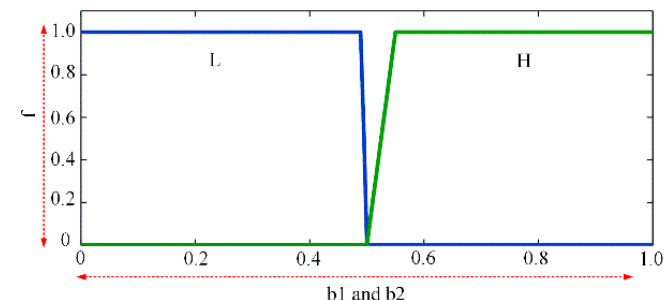

(b)

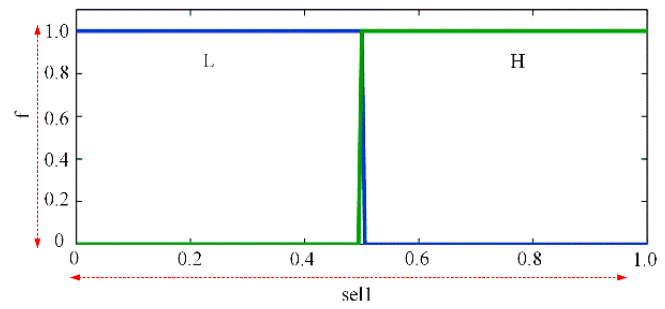

(d)

Figure 4. Membership functions of inputs and outputs for fuzzy controller. 
Table 2. Rule base of fuzzy logic controller.

\begin{tabular}{cccccc}
\hline$d \boldsymbol{P}$ & $s \boldsymbol{O C}_{\mathbf{1}}$ & $\boldsymbol{S O C}_{\mathbf{2}}$ & Sel $_{\mathbf{1}}$ & $\boldsymbol{b}_{\mathbf{1}}$ & $\boldsymbol{b}_{\mathbf{2}}$ \\
\hline $\mathrm{P}$ & $\sim \mathrm{H}$ & & $\mathrm{H}$ & $\mathrm{H}$ & $\mathrm{L}$ \\
$\mathrm{P}$ & & $\sim \mathrm{H}$ & $\mathrm{L}$ & $\mathrm{L}$ & $\mathrm{H}$ \\
$\mathrm{P}$ & $\mathrm{H}$ & $\sim \mathrm{H}$ & & $\mathrm{L}$ & $\mathrm{H}$ \\
$\mathrm{P}$ & $\sim \mathrm{H}$ & $\mathrm{H}$ & & $\mathrm{H}$ & $\mathrm{L}$ \\
$\mathrm{P}$ & $\mathrm{H}$ & $\mathrm{H}$ & & $\mathrm{L}$ & $\mathrm{L}$ \\
$\mathrm{N}$ & & $\sim \mathrm{L}$ & $\mathrm{H}$ & $\mathrm{H}$ & $\mathrm{L}$ \\
$\mathrm{N}$ & $\sim \mathrm{L}$ & & $\mathrm{L}$ & $\mathrm{L}$ & $\mathrm{H}$ \\
$\mathrm{N}$ & $\sim \mathrm{L}$ & $\mathrm{L}$ & & $\mathrm{L}$ & $\mathrm{H}$ \\
$\mathrm{N}$ & $\mathrm{L}$ & $\sim \mathrm{L}$ & & $\mathrm{H}$ & $\mathrm{L}$ \\
$\mathrm{N}$ & $\mathrm{L}$ & $\mathrm{L}$ & & $\mathrm{H}$ & $\mathrm{H}$ \\
$\mathrm{PB}$ & $\sim \mathrm{H}$ & $\sim \mathrm{H}$ & & $\mathrm{H}$ & $\mathrm{H}$ \\
$\mathrm{PB}$ & $\sim \mathrm{H}$ & $\mathrm{H}$ & & $\mathrm{H}$ & $\mathrm{L}$ \\
$\mathrm{PB}$ & $\mathrm{H}$ & $\sim \mathrm{H}$ & & $\mathrm{L}$ & $\mathrm{H}$ \\
$\mathrm{PB}$ & $\mathrm{H}$ & $\mathrm{H}$ & & $\mathrm{L}$ & $\mathrm{L}$ \\
$\mathrm{NB}$ & $\sim \mathrm{L}$ & $\sim \mathrm{L}$ & & $\mathrm{L}$ & $\mathrm{L}$ \\
$\mathrm{NB}$ & $\sim \mathrm{L}$ & $\mathrm{L}$ & & $\mathrm{L}$ & $\mathrm{H}$ \\
$\mathrm{NB}$ & $\mathrm{L}$ & $\sim \mathrm{L}$ & & $\mathrm{H}$ & $\mathrm{L}$ \\
$\mathrm{NB}$ & $\mathrm{L}$ & $\mathrm{L}$ & & $\mathrm{H}$ & $\mathrm{H}$ \\
\hline
\end{tabular}

\section{Simulation Results and Discussion}

The solar and wind data for the sizing study were recorded from a wind farm in Southern Tamil Nadu over a period of 10 days at 10-min intervals and plotted in Figure 5a. Necessary data regarding wind turbine modelling is given in Table 3 [39]. The simulations run for a period of 10 days. The Wind-PV hybrid system generates 23.205 MWh of energy during the simulation period.

Table 3. Specification of MICON M450-200.

\begin{tabular}{cccc}
\hline Specification & Value & Specification & Value \\
\hline Rated power & $200 \mathrm{~kW}$ & Cut-off speed & $25 \mathrm{~m} / \mathrm{s}$ \\
Rotor diameter & $24 \mathrm{~m}$ & Voltage & $400 \mathrm{~V}$ \\
Swept area & $452 \mathrm{~m}^{2}$ & Freq & $50 \mathrm{hz}$ \\
Blade length & $12 \mathrm{~m}$ & Air Density & $1.2258 \mathrm{~kg} / \mathrm{m}^{3}$ \\
Tip-speed ratio & $52.2 \mathrm{~m} / \mathrm{s}$ & Pitch angle & $10 \mathrm{deg}$ \\
Cut-in speed & $5 \mathrm{~m} / \mathrm{s}$ & Efficiency & $95 \%$ \\
Rated speed & $13 \mathrm{~m} / \mathrm{s}$ & & \\
\hline
\end{tabular}

\subsection{Forecasting, Dispatch Scheduling and Sizing Result}

Based on the assimilated data, forecasting is done, and the power generated from the HRES is formulated as explained in Section 2. The mean absolute percent error for wind forecasting done based on statistical analysis was $9.3 \%$ and for solar using, multiple linear regression was $12 \%$, which falls within acceptable standards [4]. The power dispatch (Dem) is then scheduled as proposed in Section 2.4. Figure $5 \mathrm{~b}$ (i) shows the scheduled power dispatch (Dem) plotted against actual power generated by the HRES for the simulation period. Figure $5 \mathrm{~b}$ (ii) is plotted for only $24 \mathrm{~h}$ to illustrate how the dispatch curve (Dem) follows peak shaving and ramp rate limiting while holding constant output for $30 \mathrm{~min}$ (two dispatch time blocks). Without any option for storage, huge power mismatches can be clearly seen here. 18.54 MWh of energy is delivered to the grid with 3.64 and 4.64 MWh energy lost due to load shedding and wind power spilling respectively. The system suffers a total Loss of Power Supply Probability (LPSP) of 19\% calculated as per the following equation

$$
\text { LPSP }=\frac{\sum \text { Energy shed }}{\sum \text { Energy delivered }} \times 100
$$




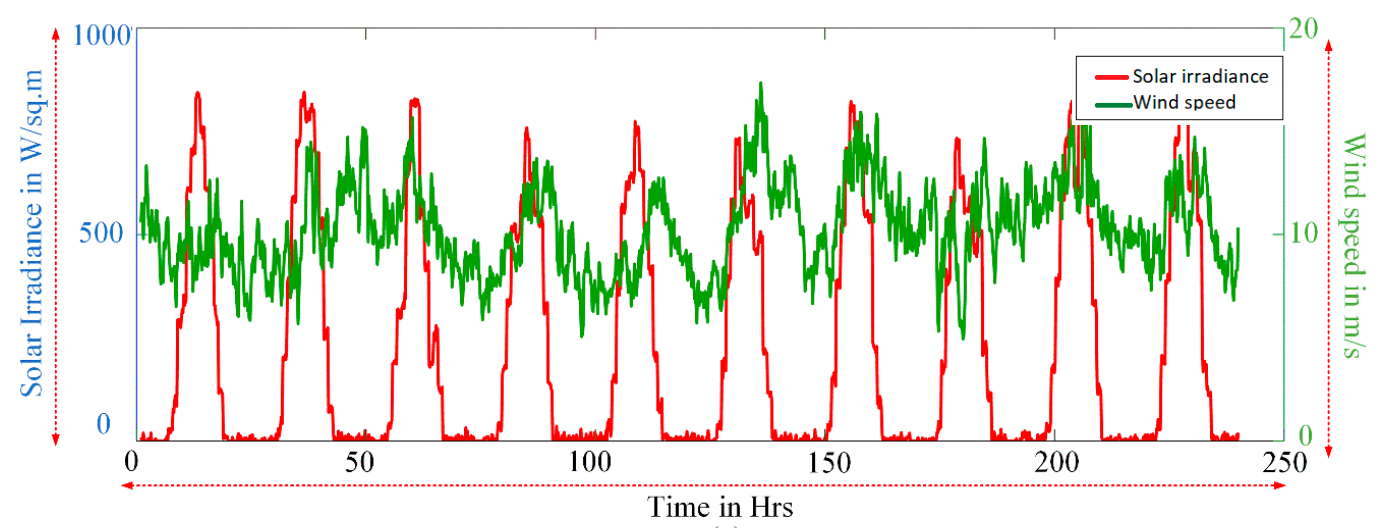

(a)

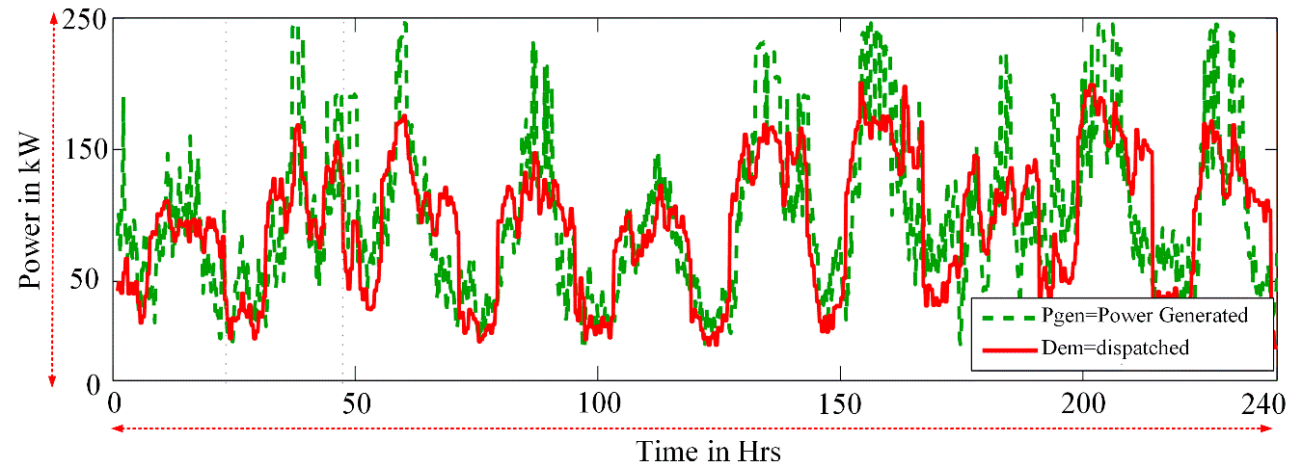

(i)

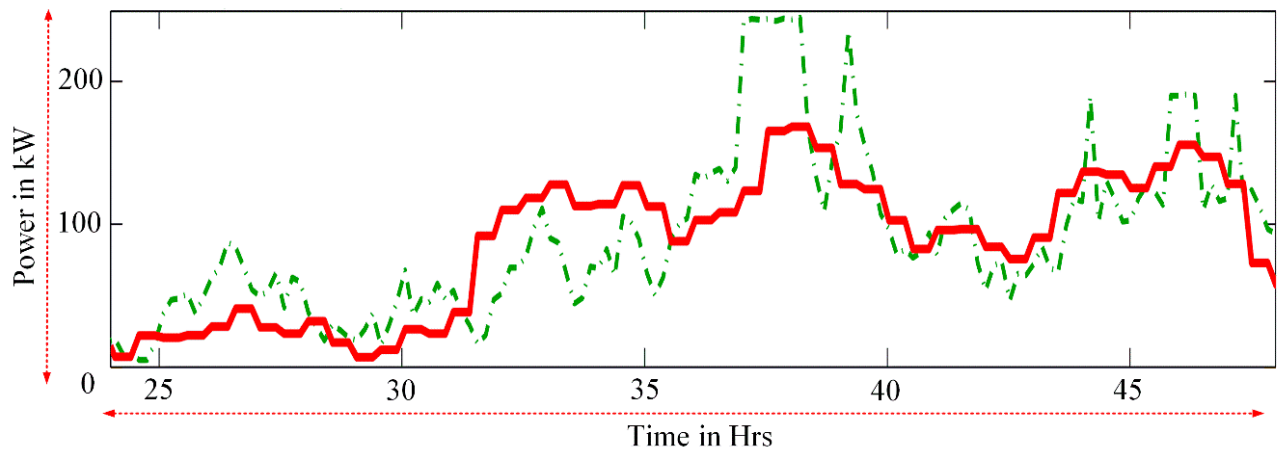

(ii)

(b)

Figure 5. (a) Wind speed and Solar irradiance (b) Forecasted power vs. Actual power generated from the Hybrid Renewable Energy System (i) 10 days; (ii) for $24 \mathrm{~h}$ simulation period.

\subsection{Single VRB Model Strategy}

The VRB characteristics considered for the study are listed in Table 4. The size of battery system found using bat algorithm is $4600 \mathrm{Ah}$ [11]. Hence, three VRB modules, each of capacity $200 \mathrm{kWh}$, are operated in parallel as a single battery bank with a capacity of $5000 \mathrm{Ah}$. The simulation results prove that the VRB enables the HRES to effectively follow the scheduled dispatch curve with a LPSP of $3.06 \%$. The battery SOC chart is plotted as in Figure 6a. The chart clearly shows underutilized battery capacity with many incomplete charging/discharging cycles, which may adversely affect the battery performance and lifetime. Figure $6 \mathrm{~b}$ represents the power delivery curves for the single battery system against $P_{\text {gen }}$. 
Table 4. Specification of VRB battery.

\begin{tabular}{cc}
\hline Specification & Value \\
\hline Type & VRB Flow Battery \\
Rating & $200 \mathrm{kWh} 120 \mathrm{~V}$ \\
Expectancy Life in years & 18 \\
Charging efficiency \% & 98 \\
Discharging efficiency $\%$ & 85 \\
Depth of Discharge & 75 \\
Cost of Battery & $600 \$ / \mathrm{kWh}$ \\
Days of Autonomy & $12 \mathrm{Rs}$ \\
\hline
\end{tabular}

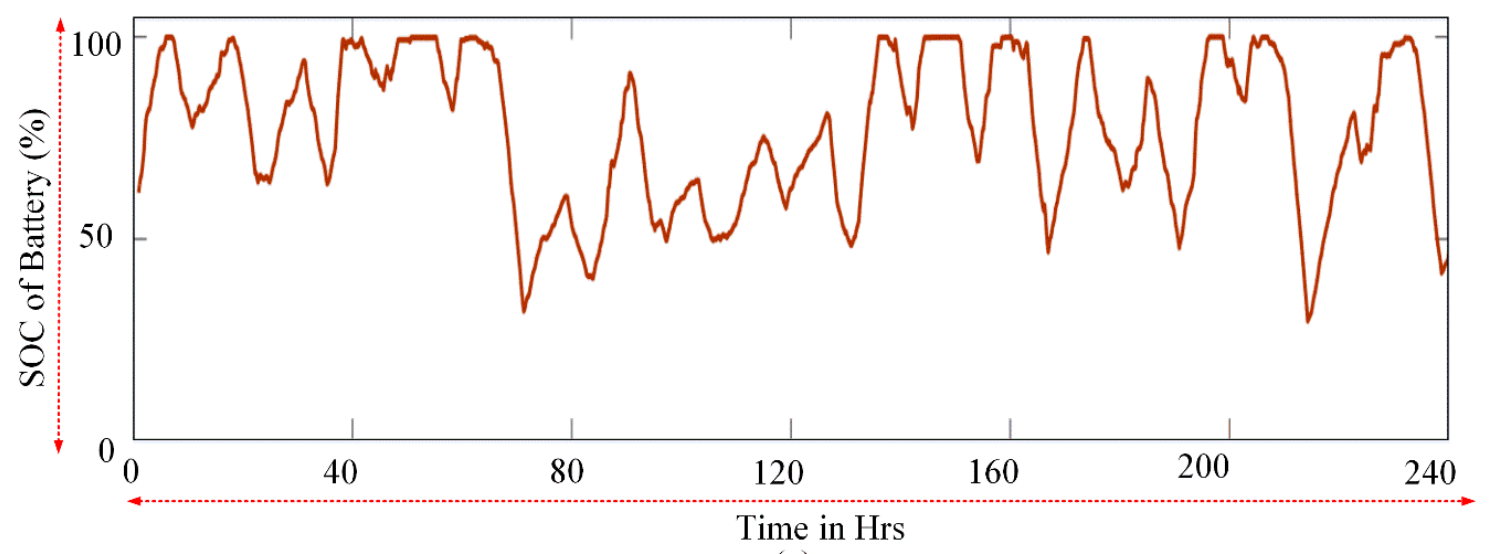

(a)

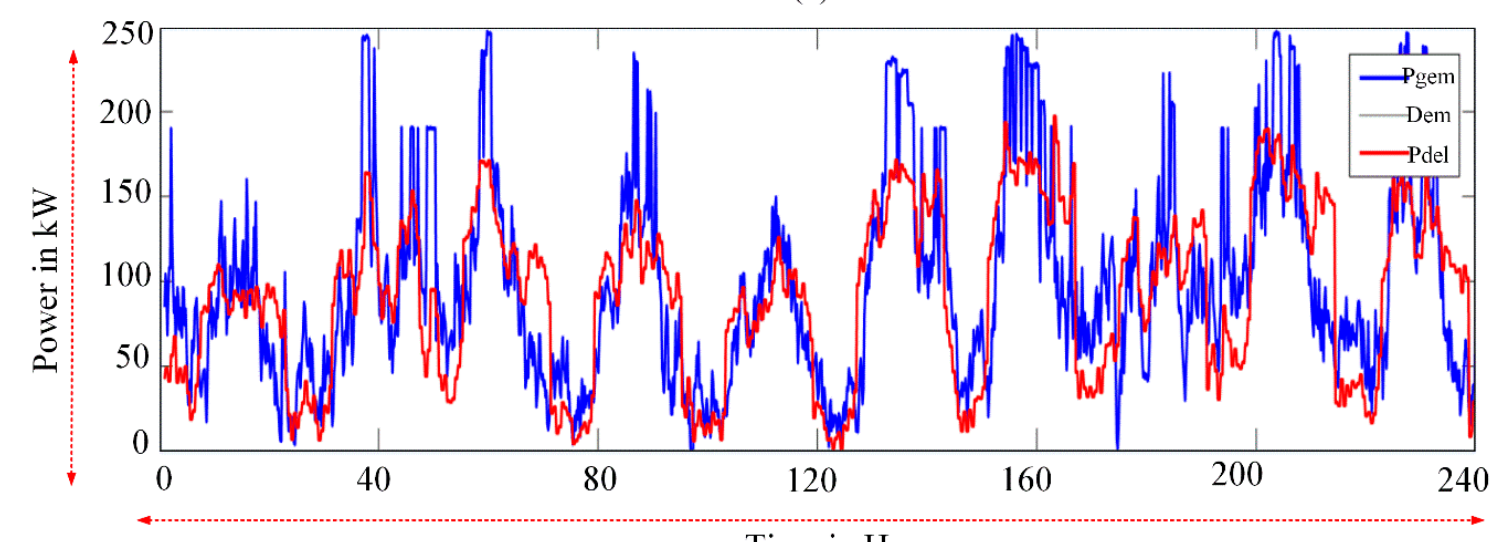

Time in $\mathrm{Hrs}$

(b)

Figure 6. Single Battery Case Simulated Results (a) State of Charge of Single VRB battery (b) Actual Power delivery $P_{\text {del }}$ plotted against Power Dispatch Dem and Power Generated $P_{g e n}$.

\subsection{Dual VRB BESS Module Strategy}

The VRB bank is now implemented in the form of two separate VRB modules: $B E S S_{1}$ and $B E S S_{2}$, each $200 \mathrm{kWh} 120 \mathrm{~V}$ (thereby two batteries of capacity $1666.66 \mathrm{Ah}$ ); connected in parallel and operated for a cumulative capacity of $400 \mathrm{kWh}(3333.33 \mathrm{Ah})$. At the beginning of the simulation period, $\mathrm{Sel}_{1}$ of $B E S S_{1}$ is held high indicating that $B E S S_{1}$ is to be charging and $B E S S_{2}$ is for discharging.

The SOC charts of the dual battery modules are shown in Figure 7a,b respectively. Figure 8a shows the power delivered by the HRES plotted against the scheduled power. This figure shows that the dispatch is being delivered as scheduled with an LPSP ratio of $4.3 \%$. The power mismatch curve is also plotted as Figure $7 \mathrm{~b}$ where the negative quadrant shows losses due to spilling and positive for the load shed. Figure 9a shows the power that is charged/discharged from the two batteries. It was observed that the FLC effectively managed the two batteries so that optimal sharing of the load was 
achieved. At times, when the difference between dispatch and generation is beyond the maximum charge/discharge limit of a single VRB module, both batteries operate together. The voltages and the currents of the individual modules in the dual battery are plotted in Figure $9 b, c$ respectively.

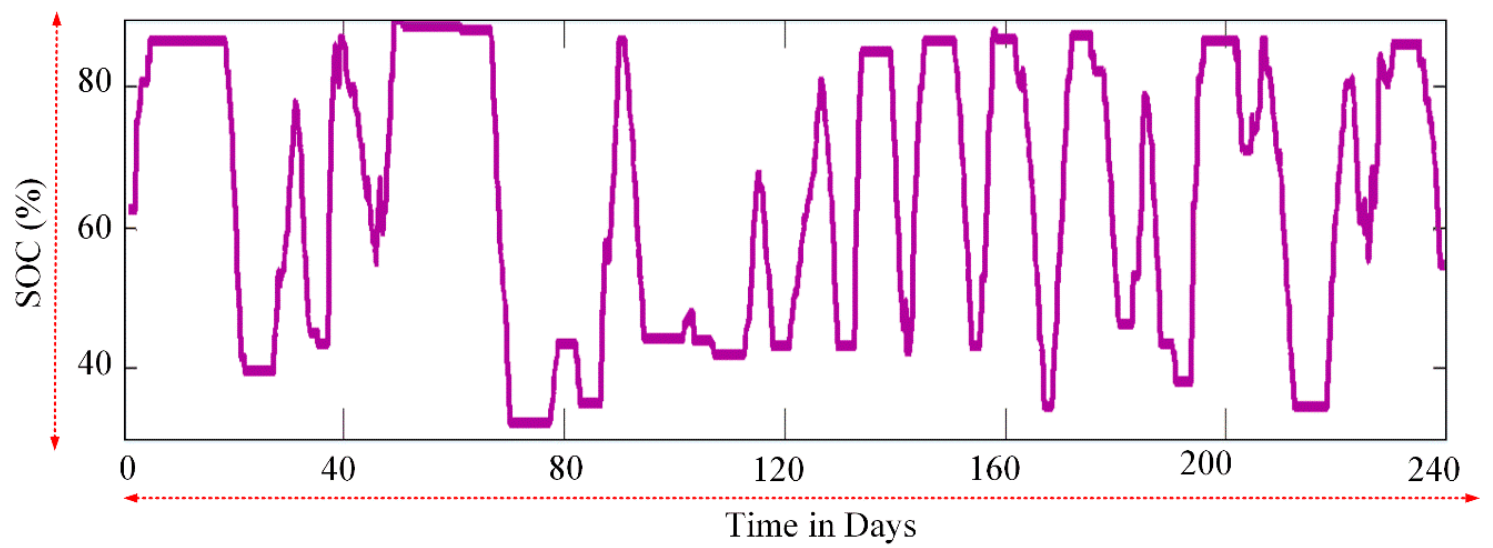

(a)

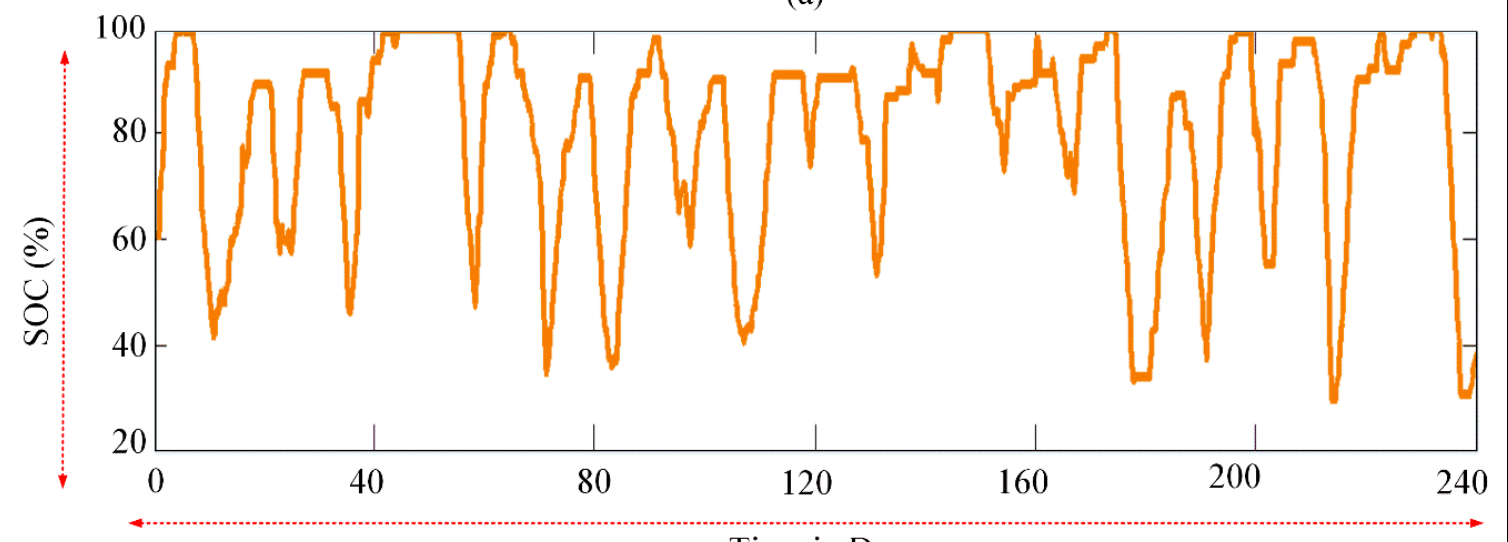

Time in Days

(b)

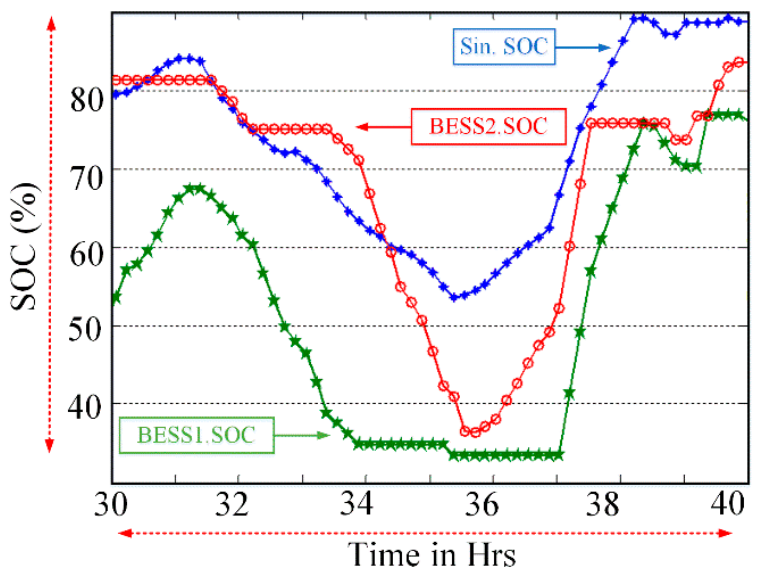

(c)

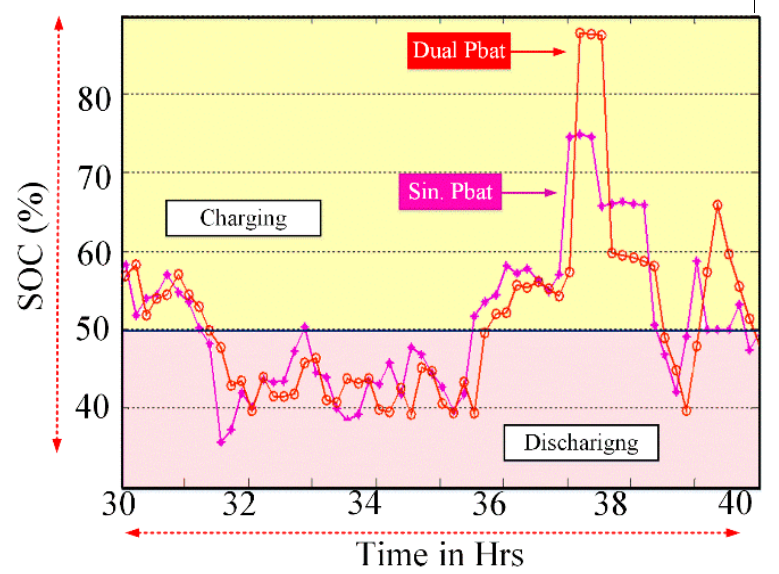

(d)

Figure 7. (a) State of Charge of Dual module $B E S S_{1}$ (b) State of Charge of Dual module $B E S S_{2}$ (c) State of Charge of batteries in both cases for $10 \mathrm{~h}$. (d) Power discharged from batteries in both cases for $10 \mathrm{~h}$. 


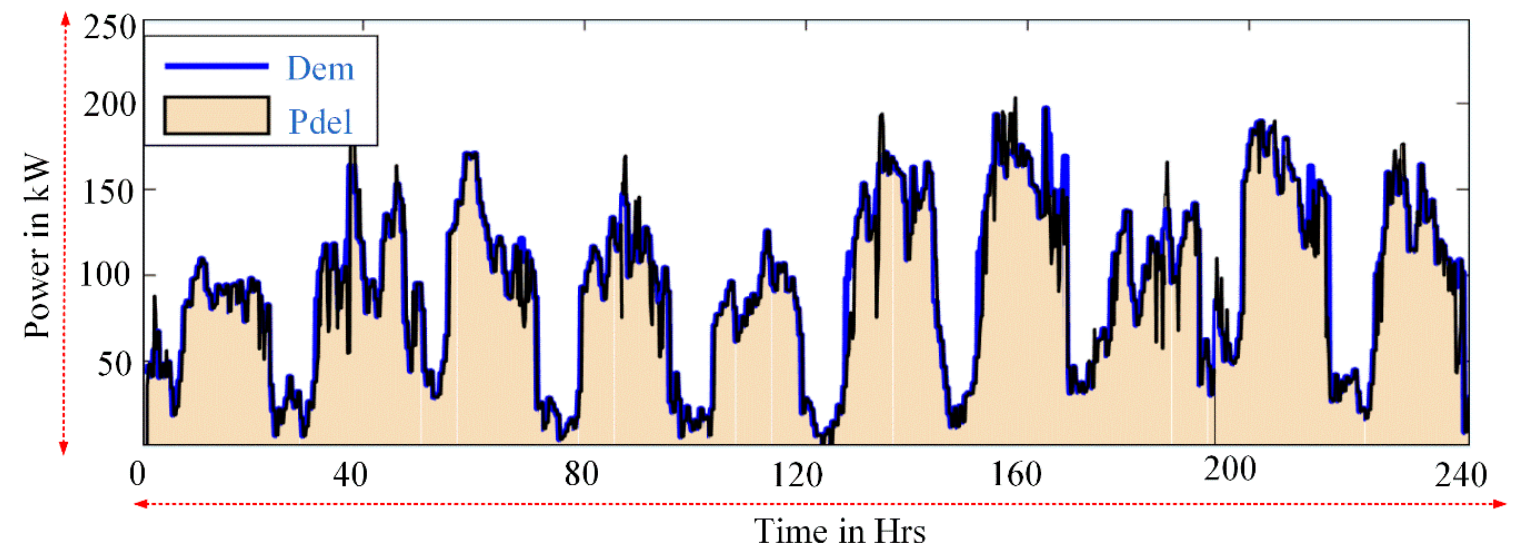

(a)

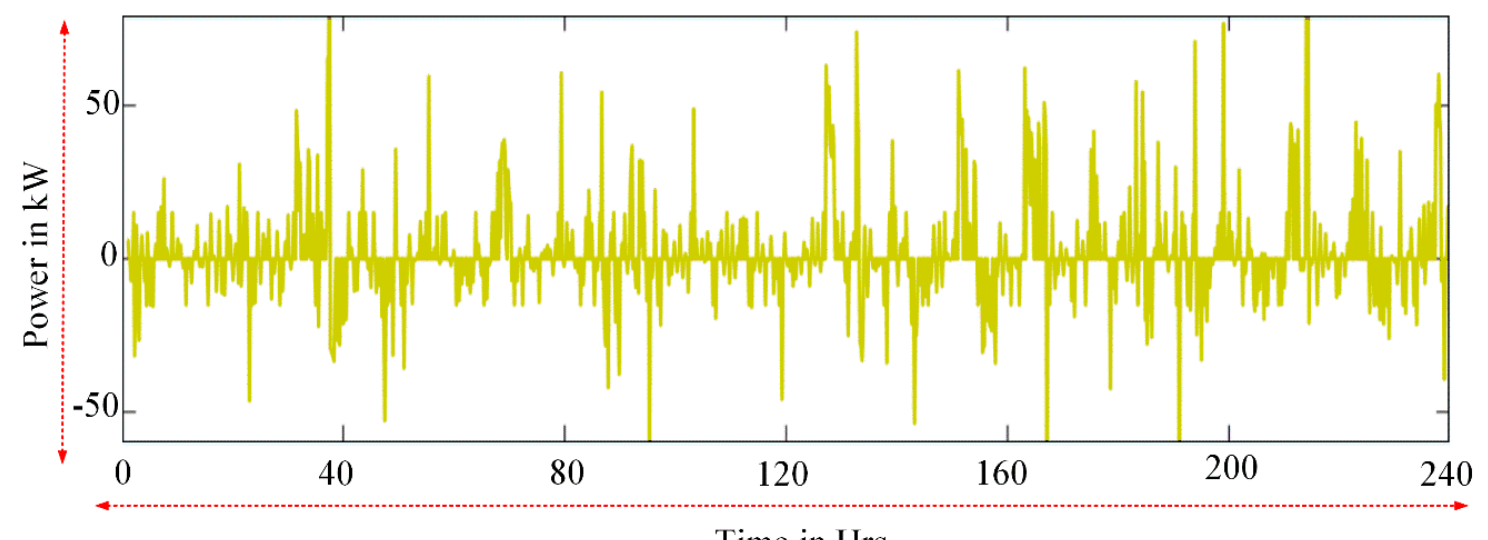

Time in Hrs

(b)

Figure 8. (a) Actual Power delivered by the HRES $P_{\text {del }}$ plotted against Power Disptach Dem (b) Power mismatch Curve (Pdel-Dem).

\subsection{Inference of Results}

Through effective energy management of VRB in the dual-battery topology, the size of the battery is now reduced to $400 \mathrm{kWh}$ modules (two batteries of $200 \mathrm{kWh}$ in parallel) as compared to the $450 \mathrm{kWh}$ of the Single Battery model with higher power limits. In Figure 7c, the SOCs of all batteries are plotted for a period of $10 \mathrm{~h}$ to illustrate the behaviour of systems. It should be noted that single battery is not a sum of the two dual batteries but a much larger system. Comparing the SOC charts from Figures 6a and $7 \mathrm{a}, \mathrm{b}$, it can be seen that in dual-model, each battery module undergoes fewer switching cycles and hence can deliver for a longer period. As a single module, VRB underwent nearly 17 charge-discharge cycles during the simulation period but it is clear that the battery capacity is underutilized as it has many incomplete charge/discharge cycles. In addition, while the VRB is used as dual-battery, the batteries did not experience more than 10-12 cycles for much-reduced size, implying a reduction of $30 \%$ of switching cycles.

Thus, with reduced size, increased life and optimized cycle operation, the dual battery strategy is clearly a more efficient and better choice than the single module case. Figure $7 \mathrm{~d}$ shows the power exchange between the battery systems and it is clear that the single battery has linear charging due to higher capacity but it needs to cater to all discharge/charge cycles and hence experiences frequent charge reversals. Whereas, in the dual case, both batteries share the charging/discharging operation and can reduce intermittent charge reversals and hence, operate better than the single battery (at instances of 37-40 h). The dual model results in a slightly higher LPSP $\approx 1 \%$ than the single module, which should be acceptable. A further understanding of the performance of the battery systems is 
explored by evaluating stress factors like the charge factor (CF), partial cycling values (PCV), time at low SOCs (TLS) and Ah Throughput of the battery; these are listed in Table 5 [40,41]. The discharge rates are usually limited by limiting the $P_{b, \max }$ for the batteries in the EMS. The results show that operating the battery modules in Single/Dual architecture has little impact on the CF or PCV values, which both prove optimal battery operation. However, the single model case suffered from very low TLS, showing underutilized capacity, which may affect the battery performance as the battery modules operate in limited charged condition characterized by low Ah Throughputs [40].

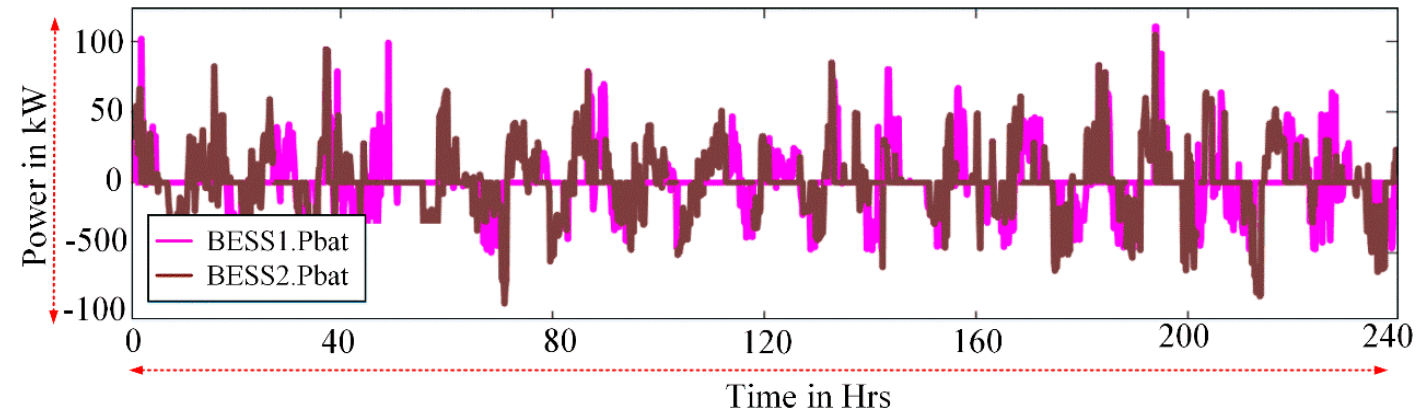

(a)

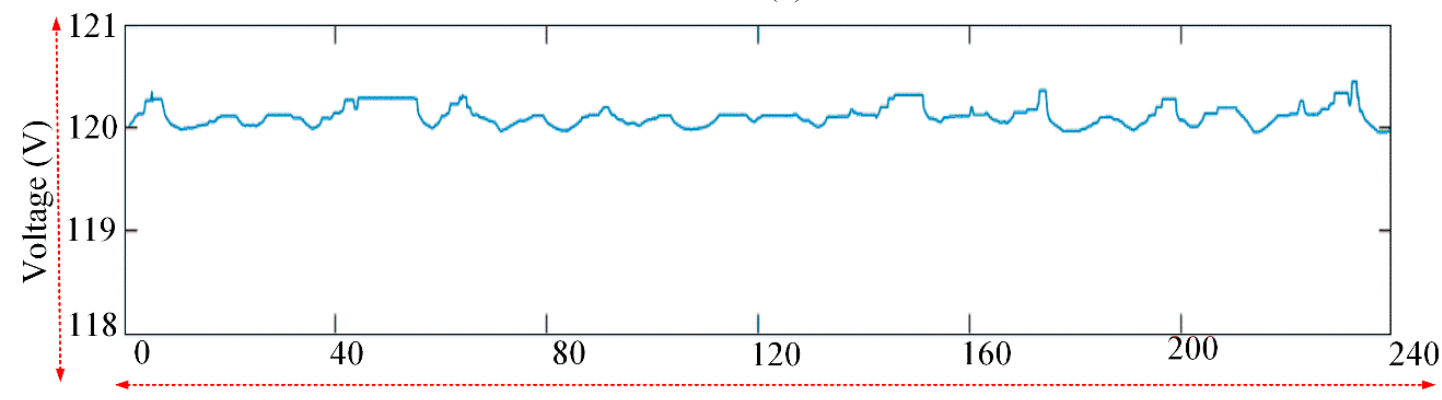

Time in Hrs

(b)

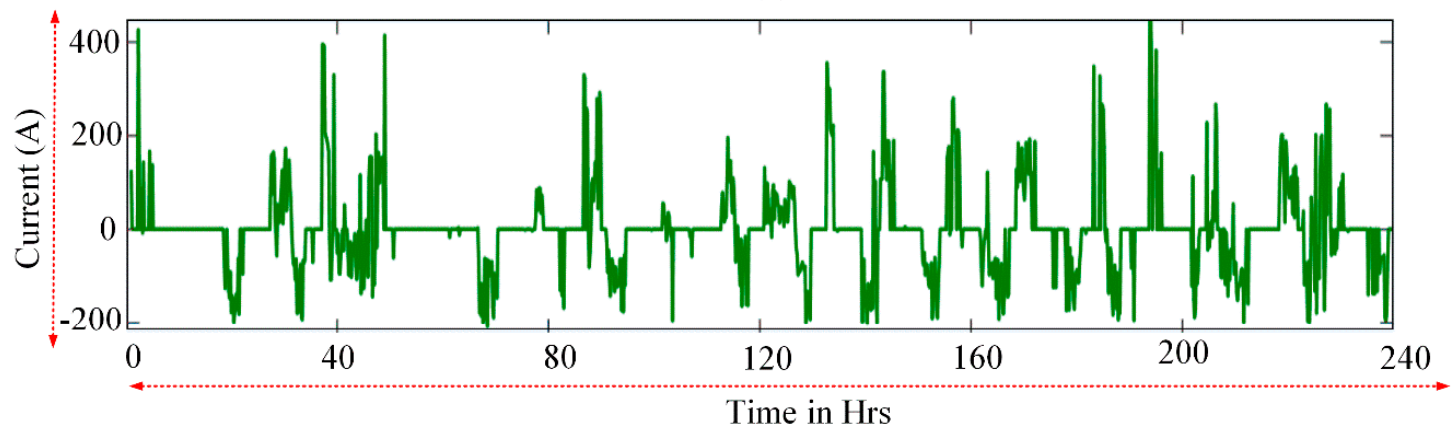

(c)

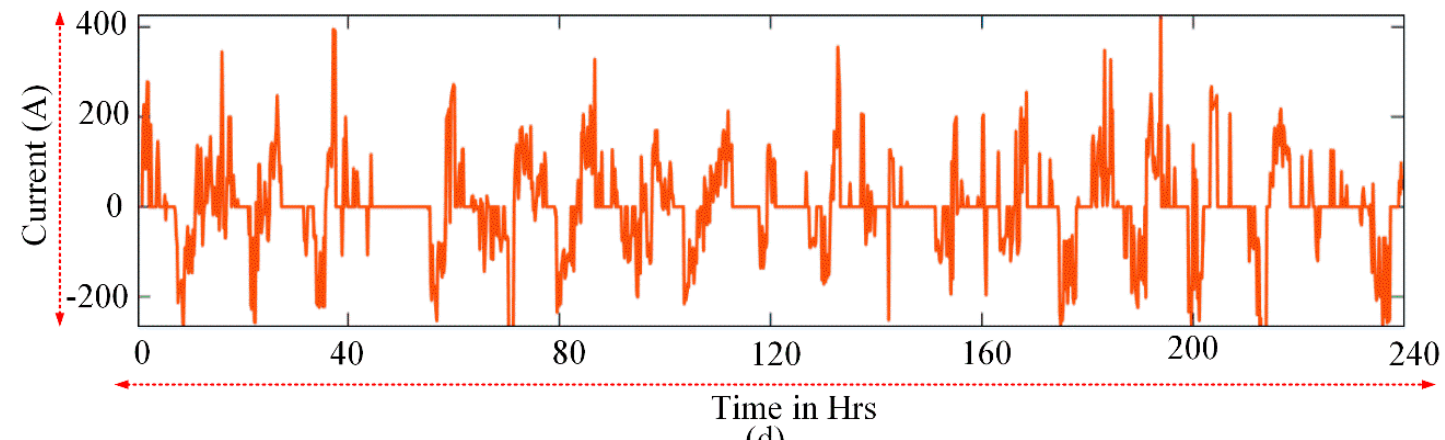

(d)

Figure 9. (a) Power Charged or Discharged by Dual battery modules $B E S S_{1}$ and $B E S S_{2}$. (b) $B E S S_{1}$ and $B E S S_{2}$ discharging voltage. (c) $B E S S_{1}$ charging and discharging current (d) $B E S S_{2}$ charging and discharging current for discharging. 
Table 5. Comparison of HRES based on simulated results.

\begin{tabular}{|c|c|c|c|}
\hline Specification * & $\begin{array}{l}\text { Without } \\
\text { Battery }\end{array}$ & $\begin{array}{c}\text { Single VRB Battery } \\
\text { Model (5000 Ah) }\end{array}$ & Dual VRB Battery Model (1666.67 Ah Each) \\
\hline \multicolumn{4}{|c|}{ Performance Parameters } \\
\hline Energy Generated (MWh) & 18.88 & 22.47 & 21.78 \\
\hline Charge Factor (CF) & & 98.10 & $B E S S_{1}-98.87 \%, B E S S_{2}-97.50 \%$ \\
\hline Ah Throughput (AHT) & & 7.055 & $B E S S_{1}-6.85, B_{E S S_{2}}-8.6$ \\
\hline Time at Low SOC (TLS) & & $0.89 \%$ & $B_{E S S_{1}}-7.88 \%, B^{2} S S_{2}-3.04 \%$ \\
\hline Partial Charging Value (PCV) & & $44.85 \%$ & $B E S S_{1}-58.03 \%, B E S S_{2}-48.93 \%$ \\
\hline Energy Generated (MWh) & 18.88 & 22.47 & 21.78 \\
\hline \multicolumn{4}{|c|}{ Economic Parameters } \\
\hline Revenue Earned (\$) & 865 & 1030.79 & 1000.04 \\
\hline Losses due to Spilling (MWh) & 4.6 & 1.076 & 0.65 \\
\hline Losses Due to Shedding (MWh) & 3.64 & 0.13 & 1.05 \\
\hline Total Losses in $\$$ & 1711.667 & 491 & 78.32 \\
\hline LPSP \% & 19 & 3.06 & 4.3 \\
\hline Cost of VRB Storage in $\$$ & & 288,000 & 240,000 \\
\hline Simple Payback Period in years & & 4.8 & 4.76 \\
\hline Discounted Payback period in years & & 6.65 & 6.58 \\
\hline Benefit-to-Cost Ratio & & 1.83 & 1.94 \\
\hline Net Present Value of System in \$ & & $326,666.67$ & $313,394.27$ \\
\hline
\end{tabular}

${ }^{*}$ Note: Simulation period for 10 days.

\subsection{Economic Analysis}

Flow batteries face major barriers regarding financial concerns for implementation in wind projects. [42,43] are some articles available in the literature, which attempt to explore the cost-effectiveness of battery technologies for applications like load shifting and utility scale integration. A similar approach has been attempted to explore the investment returns of the proposed system. Assuming net investment to be $600 \$ / \mathrm{kWh}$, the total investment for the two battery modules amounts to $\$ 240,000$. An economic evaluation is carried out to understand the feasibility of investment and results tabulated in Table 5. Assume the power generated is sold to the utility at the rate of Rs. 2.75 per $\mathrm{kWh}$, as per tariff fixed by the Tamil Nadu Electricity Regulatory Commission [44]. The revenue lost due to wind power spilling and load shedding due to inadequate storage are evaluated as per (13-16). The total revenue earned by operating the Wind-PV system (without storage) is $\$ 865$ and the losses incurred is $\$ 1711$, as maximum losses occur in the form of spilled renewable power which could not be accommodated in the grid. The same calculations are repeated after implementation of VRB in both strategies. Dual VRB HRES delivers 21.78 MWh of energy thus earning a total amount $\$ 1000.04$. The losses now amount to $\$ 78.32$. Thus, a total of about $\$ 1767$ is saved in 10 days. Then the annual savings will amount to nearly $\$ 63,636$. Thus, the battery investment can be earned back within five years of installation and it almost equals the payback for single case. If interest rates and inflation rates are to be considered (assume ir $=12 \%$, ifr $=7 \%$ and $\gamma=3 \%$ ) then the discounted payback period increases to about seven years. The total lifetime of the VRB, assuming it delivers 10000 cycles, is approximately 20 years (No. of battery cycles $=13$ in 10 days). Thus, the system has a Net Present Value of $\$ 313,400$ and a positive Benefit to Cost ratio of 1.949 , both higher than the single battery case due to lesser investment costs. These values clearly prove that VRB investment for peak shaving in this Wind-PV system is highly profitable.

\section{Conclusions}

The proposed strategy for integration of VRB with the Wind-PV system has enabled the intermittent renewable generation unit to be considered as a dispatchable firm power-generating unit. The renewable system has been scheduled based on the forecasted wind speed data with strategic redistribution of generated power to meet peak loads using a VRB battery. The VRB size required to meet this scheduled dispatch has been evaluated using a meta-heuristic optimization algorithm. The VRB has been modeled for two cases as single and dual-battery models in Matlab/Simulink 
environment and the simulations have been carried out on real-time data from a wind farm in Southern Tamil Nadu, India. The simulated results have proved that operating the dual battery with an intelligent energy management strategy reduces battery size by $20 \%$ and significantly lowers investment costs. In addition, reduced switching cycles of batteries has improved the service lifetime of the VRB with better TLS, proving optimum usage of battery. A simple economic analysis has been presented which concludes that investment in VRB for the proposed application is profitable with early paybacks.

Author Contributions: All authors contributed equally for the investigation task and presented the article in its final format as full research work outcome.

Funding: This research received no external funding.

Acknowledgments: We authors like to acknowledge the support received from Aalborg University-'Initiative Research Pool Fund' to carry out this research work for its final presentation and outcomes. In addition, we like to express Jens Bo-Helm Nielsen, Head of the Energy Esbjerg Section/Center for Bioenergy and Green Engineering, Aalborg University, Esbjerg Section, Denmark for sharing his insight technical expertise in the field of renewable and sustainable energy.

Conflicts of Interest: The authors declare no conflict of interest.

\section{Nomenclature}

$\alpha \quad$ Temperature coefficient of PV panel

$\gamma \quad$ Ratio of battery maintenance cost to the fixed cost

$\rho \quad$ Air density in $\mathrm{kg} / \mathrm{m}^{3}$

$\chi \quad$ Energy cost coefficient of the VRB in $\$ / \mathrm{kWh}$

$\eta_{w t} \quad$ Efficiency of the wind turbine

$\eta_{p v} \quad$ Efficiency of solar inverter

$\eta_{\text {ch }} ; \eta_{\text {dis }} \quad$ Charging/discharging efficiency of the VRB

$f_{p v} \quad$ Derating factor for PV panel

ir Interest rate \%,

ifr Inflation rate \%

idr Discount rate

$n \quad$ VRB lifetime in years.

A Swept area in $\mathrm{m}^{2}$ of wind turbine

$C_{\text {vrb }} \quad$ Energy capacity of VRB in $\mathrm{kWh}$

$(t) \quad$ Energy stored in VRB at time $t$ in $\mathrm{kWh}$

$(t) \quad$ VRB Power charged/discharged at $t$ in $\mathrm{kW}$

$P_{\text {del }}(t) \quad$ Power delivered by the HRES at time $t$ in $\mathrm{kW}$

$\operatorname{Dem}(t) \quad$ Power to be dispatched to the load at time $t$ in $\mathrm{kW}$

$P_{g e n}(t) \quad$ Power generated by the wind-PV at time $t$ in $\mathrm{kW}$

$P_{p v}(t) \quad$ Power generated by the solar panel at time $t$ in $\mathrm{kW}$

$P_{\omega} \quad$ Power generated by wind turbine in $\mathrm{kW}$

$P R_{d} \quad$ Diesel power cost in Rs $/ \mathrm{kWh}$

$P R_{w s} \quad$ Selling price of wind power in Rs $/ \mathrm{kWh}$

$R \quad$ Gas Constant

$T \quad$ Temperature in ${ }^{\circ} \mathrm{C}$

SOC $(t)$ State of Charge of the VRB at time $t$

\section{References}

1. Indian Wind Turbine Manufacturers Association. Indian Wind Power Magazine-Repowering Issue; Indian Wind Turbine Manufacturers Association: New Delhi, India, 2015.

2. International Renewable Energy Agency. Battery Storage for Renewables: Market status and Technology Outlook; International Renewable Energy Agency: Abu Dhabi, UAE, 2015.

3. Mateo, A.R. Assessment of the Contribution of Storage and Demand Side Management to Power System Flexibility. Master's Thesis, The University of Manchester, Manchester, UK, 2011. 
4. Cervone, A.; Carbone, G.; Santini, E.; Teodori, S. Optimization of the battery size for PV systems under regulatory rules using a Markov-Chains approach. Renew. Energy 2016, 85, 657-665. [CrossRef]

5. Ganesan, S.; Padmanaban, S.; Varadarajan, R.; Subramaniam, U.; Mihet-Popa, L. Study and analysis of an intelligent microgrid energy management solution with distributed energy sources. Energies 2017, 10, 1419. [CrossRef]

6. Fathima, A.H.; Palanisamy, K. Battery energy storage applications in wind integrated systems-A review. In Proceedings of the International Conference Smart Electric Grid (ISEG'14), Guntur, India, 19-20 September 2014; pp. 1-8.

7. Das, V.; Padmanaban, S.; Venkitusamy, P.; Selvamuthukumaran, R.; Blaabjerg, F.; Siano, P. Recent advances and challenges of fuel cell based power system architectures and control-A review. Renew. Sustain. Energy Rev. 2017, 73, 10-18. [CrossRef]

8. Vavilapalli, S.; Padmanaban, S.; Subramaniam, U.; Mihet-Popa, L. Power balancing control for grid energy storage system in photovoltaic applications-Real time digital simulation implementation. Energies 2017, 10, 928. [CrossRef]

9. Ranaweera, I.; Midtgård, O. Optimization of operational cost for a grid-supporting PV system with battery storage. Renew. Energy 2016, 88, 262-272. [CrossRef]

10. Park, A.; Lappas, P. Evaluating demand charge reduction for commercial-scale solar PV coupled with battery storage. Renew. Energy 2016, 108, 523-532. [CrossRef]

11. Fathima, A.H.; Palanisamy, K. Optimized sizing, selection, and economic analysis of battery energy storage for grid-connected wind-PV hybrid system. Model. Simul. Eng. 2015, 2015, 71353. [CrossRef]

12. Junyent-Ferré, A.; Gomis-Bellmunt, O.; Sumper, A.; Sala, M.; Mata, M. Modeling and control of the doubly fed induction generator wind turbine. Simul. Model. Pract. Ther. 2010, 18, 1365-1381. [CrossRef]

13. Koohi-Kamali, S.; Tyagi, V.V.; Rahim, N.A.; Panwar, N.L.; Mokhlis, H. Emergence of energy storage technologies as the solution for reliable operation of smart power systems: A review. Renew. Sustain. Energy Rev. 2013, 25, 135-165. [CrossRef]

14. Viswanathan, V.; Crawford, A.; Stephenson, D.; Kim, S.; Wang, W.; Li, B.; Coffey, G.; Thomsen, E.; Graff, G.; Balducci, P.; et al. Cost and performance model for redox flow batteries. J. Power Sources 2014, 247, 1040-1051. [CrossRef]

15. DOE Global Energy Storage Database. Available online: http://www.energystorageexchange.org/ (accessed on 4 September 2018).

16. Vieira, F.M.; Moura, P.S.; de Almeida, A.T. Energy storage system for self-consumption of photovoltaic energy in residential zero energy buildings. Renew. Energy 2017, 103, 308-320. [CrossRef]

17. Padmanaban, S.; Blaabjerg, F.; Wheeler, P.; Ojo, J.O.; Ertas, A.H. High-voltage dc-dc converter topology for pv energy utilization-Investigation and implementation. Electr. Power Compon. Syst. 2017, 45, 221-232. [CrossRef]

18. Mahajan, S.B.; Padmanaban, S.; Blaabjerg, F. A Multistage DC-DC Step-Up Self-Balanced and Magnetic Component-Free Converter for Photovoltaic Applications: Hardware Implementation. Energies 2017, 10, 719.

19. Ameen, A.M.; Pasupuleti, J.; Khatib, T. Simplified performance models of photovoltaic/diesel generator/battery system considering typical control strategies. Energy Convers. Manag. 2015, 99, 313-325. [CrossRef]

20. Yao, D.L.; Choi, S.S.; Tseng, K.J.; Lie, T.T. A statistical approach to the design of a dispatchable wind power-battery energy storage system. IEEE Trans. Energy Convers. 2009, 24, 916-925. [CrossRef]

21. Yao, D.L.; Choi, S.S.; Tseng, K.J.; Lie, T.T. Determination of short-term power dispatch schedule for a wind farm incorporated with dual-battery energy storage scheme. IEEE Trans. Sustain. Energy 2012, 3, 74-84. [CrossRef]

22. Abdullah, M.A.; Muttaqi, K.M.; Sutanto, D.; Agalgaonkar, A.P. An effective power dispatch control strategy to improve generation schedulability and supply reliability of a wind farm using a battery energy storage system. IEEE Trans. Sustain. Energy 2015, 6, 1093-1102. [CrossRef]

23. Cao, J.; Du, W.; Wang, H.; McCulloch, M. Optimal Sizing and Control Strategies for Hybrid Storage System as Limited by Grid Frequency Deviations. IEEE Trans. Power Syst. 2018, 33, 5486-5495. [CrossRef]

24. Athari, M.H.; Ardehali, M.M. Operational performance of energy storage as function of electricity prices for on-grid hybrid renewable energy system by optimized fuzzy logic controller. Renew. Energy 2016, 85, 890-902. [CrossRef] 
25. Hua, G.; Lia, J.; Zeng, G. Recent development in the treatment of oily sludge from petroleum industry: A review. J. Hazard. Mater. 2013, 261, 470-490. [CrossRef] [PubMed]

26. Noack, J.; Wietschel, L.; Roznyatovskaya, N.; Pinkwart, K.; Tübke, J. Techno-Economic Modeling and Analysis of Redox Flow Battery Systems. Energies 2016, 9, 627. [CrossRef]

27. Fathima, A.H.; Palanisamy, K. Modeling and operation of a Vanadium Redox Flow Battery for storage in a stand-alone PV system. Energy Procedia 2017, 117, 607-614. [CrossRef]

28. GIZ. India Green Energy Corridors IGEN-GEC: Report on Forecasting, Concept of Renewable Energy Management Centres and Grid Balancing; Deutsche Gesellchaft fur Internationale Zusammenarbeit (GIZ): Frankfurt, Germany, May 2015.

29. Lydia, M.; Kumar, S.; Selvakumar, A.I.; Kumar, G.E.P. A comprehensive review on wind turbine power curve modeling techniques. Renew. Sustain. Energy Rev. 2014, 30, 452-460. [CrossRef]

30. Lydia, M.; Kumar, S.; Selvakumar, A.I.; Kumar, G.E.P. Advanced Algorithms for Wind Turbine Power Curve Modeling. IEEE Trans. Sustain. Energy 2013, 4, 827-835. [CrossRef]

31. Liu, M.; Quilumba, G.E.P.; Lee, W. Dispatch scheduling for a wind farm with hybrid energy storage based on wind and LMP forecasting. IEEE Trans. Ind. Appl. 2015, 51, 970-1977. [CrossRef]

32. Abuella, M.; Chowdhury, B. Solar power probabilistic forecasting by using multiple linear regression analysis. In Proceedings of the International Conference IEEE SoutheEast Conference, Lauderdale, FL, USA, 9-12 April 2015.

33. Nguyen, C.; Lee, H.; Chun, T. Cost-optimized battery capacity and short-term power dispatch control for wind farm. IEEE Trans. Ind. Appl. 2015, 51, 595-606. [CrossRef]

34. Ali, A.; Padmanaban, S.; Twala, B.; Marwala, T. Electric Power Grids Distribution Generation System for Optimal Location and Sizing-A Case Study Investigation by Various Optimization Algorithms. Energies 2017, 10, 960.

35. Yang, X. A new metaheuristic bat-inspired algorithm. In Proceedings of the Nature Inspired Cooperative Strategies for Optimization (NICSO 2010), Granada, Spain, 12-14 May 2010; pp. 65-74.

36. Khan, K.; Sahai, A. A Comparison of BA, GA, PSO, BP and LM for Training Feed forward Neural Networks in e-Learning Context. Int. J. Intell. Syst. Appl. 2012, 4, 23-29. [CrossRef]

37. Hegazy, O.; Soliman, O.S.; Salam, M.A. Comparative Study between FPA, BA, MCS, ABC, and PSO Algorithms in Training and Optimizing of LS-SVM for Stock Market Prediction. Int. J Adv. Comput. Res. IJACR 2015, 5, 35-45.

38. Berrazouane, S.; Mohammedi, K. Parameter optimization via cuckoo optimization algorithm of fuzzy controller for energy management of a hybrid power system. Energy Convers. Manag. 2014, 78, 652-660. [CrossRef]

39. Available online: http:/ / en.wind-turbine-models.com/turbines/256-micon-m-450 (accessed on 3 October 2018).

40. Svoboda, V.; Wenzl, H.; Kaiser, R.; Jossen, A.; Baring-Gould, I.; Manwell, J.; Lundsager, P.; Bindner, H.; Cronin, T.; Nørgård, P.; et al. Operating conditions of batteries in off-grid renewable energy systems. Sol. Energy 2007, 81, 1409-1425. [CrossRef]

41. Lujano-Rojas, J.M.; Dufo-López, R.; Atencio-Guerra, J.L.; Rodrigues, E.M.; Bernal-Agustín, J.L.; Catalão, J.P. Operating conditions of lead-acid batteries in the optimization of hybrid energy systems and microgrids. Appl. Energy 2016, 179, 590-600. [CrossRef]

42. Chua, K.H.; Lim, Y.S.; Morris, S. Cost-benefit assessment of energy storage for utility and customers: A case study in Malaysia. Energy Convers. Manag. 2015, 106, 1071-1081. [CrossRef]

43. Han, X.; Ji, T.; Zhao, Z.; Zhang, H. Economic evaluation of batteries planning in energy storage power stations for load shifting. Renew. Energy 2015, 78, 643-647. [CrossRef]

44. Tamil Nadu Electricity Regulatory Commission. Determination of Tariff for Generation and Distribution; T.P. No. 1; Tamil Nadu Electricity Regulatory Commission: Tamil Nadu, India, 2013.

(C) 2018 by the authors. Licensee MDPI, Basel, Switzerland. This article is an open access article distributed under the terms and conditions of the Creative Commons Attribution (CC BY) license (http://creativecommons.org/licenses/by/4.0/). 